\title{
Limitations of primary angioplasty in acute myocardial infarction
}

\author{
Effectiveness depends on the clinical and operational context
}

Coronary angioplasty as a primary method for establishing coronary patency in patients with acute myocardial infarction is riding the crest of a wave of enthusiasm that threatens to engulf us and carry us off into uncritical adoption. It is thus appropriate to examine the advantages and limitations of the procedure before we allow it to proliferate unchecked.

THE CASE FOR PRIMARY ANGIOPLASTY: CLINICAL TRIALS Seven randomised, controlled clinical trials enrolling a total of 1064 patients have evaluated the benefits of primary angioplasty in acute myocardial infarction. ${ }^{1-7}$ The major advantages of PTCA over thrombolysis stem from its ability to deal with the underlying coronary stenosis as well as achieving coronary patency. This translated into significantly fewer recurrent ischaemic events. ${ }^{35}$ PTCA patients showed a reduction in the combination of recurrent infarction, angina, need for subsequent emergency revascularisation procedures, and death as compared with thrombolysis patients. ${ }^{35}$ Two studies reported improved ventricular function in PTCA patients, ${ }^{15}$ whereas another showed no improvement in ventricular function, ${ }^{2}$ and another did not show a greater degree of myocardial preservation as assessed by nuclear perfusion imaging. ${ }^{4}$ The impact on mortality is less firmly established because most of the individual trials did not have sufficient power to address this question. However, de Boer $e t$ al reported a reduction in mortality ${ }^{5}$ and a post-hoc subgroup analysis by the Primary Angioplasty in Myocardial Infarction study group showed a significant reduction in mortality among high risk patients. ${ }^{8} \mathrm{~A}$ meta-analysis of all the clinical trials showed that mortality in PTCA patients is less than half that in thrombolysis patients. ${ }^{9}$

Strokes were more common in thrombolysis patients ${ }^{35}$ but the overall rates of serious haemorrhage were no different in PTCA and thrombolysis patients. ${ }^{45}$ Because of differences in the mechanism of haemorrhage (systemic thrombolysis versus vascular invasion), PTCA may be useful in patients with contraindications to thrombolysis. Preliminary data from one controlled clinical trial suggest that primary angioplasty improves outcome as compared with conservative therapy without attempted recanalisation in patients who are not eligible for thrombolysis. ${ }^{10}$

\section{LIMITATIONS OF PRIMARY ANGIOPLASTY}

Timing and availability

Most patients with acute myocardial infarction present to hospitals without catheterisation laboratories. Thrombolysis is an effective, universally available treatment that can be administered rapidly. To deliberately withhold thrombolysis and impose the delays inherent in transferring thrombolysis-eligible patients for primary PTCA would be counter productive. Transferring patients who have absolute contraindications to thrombolysis to institutions with PTCA facilities may be justifiable, however. Transportation will necessarily compromise rapid recanalisation and will reduce the effectiveness of PTCA. In every trial comparing PTCA and thrombolysis, treatment was delivered sooner to patients assigned to thrombolytic therapy. ${ }^{9}$ These time differences occurred in centres committed to offering primary PTCA which had confirmed track records in emergency, round-the-clock interventional cardiology services. ${ }^{11}$ Any hospital contemplating offering primary PTCA must examine its ability and willingness to devote the necessary resources to treating patients sufficiently quickly.

Direct angioplasty for myocardial infarction without surgical back-up

The American College of Cardiology/American Heart Association (ACC/AHA) Committee on PTCA has recognised that PTCA in Canada and Europe is frequently performed in centres without facilities for surgery. ${ }^{12}$ In the United States, where surgical programmes are more widespread, this authoritative committee has deemed it mandatory that PTCA be performed only in centres with on-site surgical back-up. ${ }^{12}$ This same committee, however, has suggested that because it offers significant benefits over thrombolysis, primary PTCA may be offered even in catheterisation laboratories without on-site surgical back-up. ${ }^{12}$ The suspension of the requirements for on-site surgical back-up may be premature.

This proposal disregards the fact that in the clinical trials more patients in the PTCA arm underwent emergency bypass surgery (either as primary therapy or as salvage after failed angioplasty) than in the thrombolysis arm and this may have been an important factor in the reported superiority of the invasive strategy. Undertaking primary PTCA at a site without surgical backup may negate the advantages of the invasive strategy.

Efficiency and skill are the byproducts of repeated practice. Because operational volume has been recognised as a major determinant of success and complication rates and has resulted in formal recommendations for minimum operator and laboratory volume requirements, ${ }^{12}$ it is inconsistent and counterintuitive to relinquish the most urgent and potentially unstable PTCA patients to the least experienced, part-time laboratories. A stock of balloons and guiding catheters does not convert a diagnostic catheterisation laboratory into an interventional laboratory. It is unlikely that institutions new to this business will replicate the success rates, complication rates, and timeliness of response that were achieved in the centres that reported the favourable PTCA results. Furthermore, if these new laboratories subsequently refrain from providing elective PTCA services because of their lack of surgical back-up, their inexperience will be permanent.

Costs

Gibbons et al examined hospital charges and indirect measures of cost such as return to work. ${ }^{4}$ Because of shorter hospital stays and fewer readmissions for recurrent ischaemia, treatment with PTCA cost less than thrombolysis. ${ }^{4}$ This study of a PTCA-based strategy was performed in an American centre and its results may not be universally applicable. Furthermore, the thrombolytic 
agent in this trial was t-PA. Centres using less expensive thrombolytic agents would find less of a relative cost advantage in PTCA. Finally, the hospital in this study had a well-established interventional catheterisation laboratory. Therefore, the marginal cost associated with expanding PTCA services to encompass an additional cohort of patients was fairly small. The costs to hospitals that do not offer PTCA or are not yet staffed to provide PTCA 24 hours a day will be greater than those reported in this study.

\section{Cardiogenic shock}

Because of the continued dismal prognosis of cardiogenic shock the medical community is primed and anxious to embrace any intervention that offers a glimmer of hope. In this spirit the ACC/AHA Committee on PTCA recently concluded that for patients "in cardiogenic shock with or without previous thrombolytic therapy and within twelve hours of the onset of symptoms" there is "general agreement that coronary angioplasty is justified" (class I

\section{"There have been no randomised, prospective, controlled clinical trials of PTCA in cardiogenic shock"}

indication)..$^{12}$ There have been no randomised, prospective, controlled clinical trials of PTCA in cardiogenic shock. All of the reports to date have been retrospective reports of experience with PTCA. Eighteen studies enrolling 702 patients treated with direct coronary angioplasty for cardiogenic shock showed a relatively high survival in patients with cardiogenic shock undergoing successful angioplasty $(69 \cdot 3 \%){ }^{13}$ However, because the mortality of patients with unsuccessful angioplasties remains high, the overall survival of patients with cardiogenic shock undergoing PTCA was $55.6 \% .^{13}$ It is difficult to compare this PTCA mortality with the $90 \%$ mortality rate in historical controls. ${ }^{14}$ The survival rate of conservatively managed patients in the studies of PTCA (when they were reported) was $35 \cdot 5 \%,{ }^{13}$ with one trial reporting a survival rate of $79 \% .{ }^{15}$ This underscores important variations in the definition of cardiogenic shock. Furthermore, a significant selection bias may be exerting a spurious favourable influence on mortality in PTCA patients. If moribund patients never reach the catheterisation laboratory, PTCA patients will constitute a relatively healthy population. This possibility is increased by reports suggesting that patients excluded from PTCA received less intensive supportive treatment ${ }^{16}$ or that excluded patients were more ill than patients taken to the catheterisation laboratory. ${ }^{17}$

Because attempts at randomised controlled trials have been thwarted by the reluctance of physicians to randomise patients to conservative therapy, ${ }^{18}$ the impact of PTCA can only be evaluated by examining temporal trends in case fatality rates. Thus in five or 10 years it will be appropriate to reassess whether the mortality associated with cardiogenic shock has fallen during the interventional era.

CONCLUSIONS

The clinical benefits of direct PTCA for acute myocardial infarction are substantial and well validated. The application of primary PTCA, however, is expanding beyond the limits of the scientific data. The considerable benefits of primary angioplasty were established in specific clinical and operational contexts. Moving primary PTCA beyond these contexts will probably reduce its effectiveness. Proposals to do so should be greeted with a generous dose of scepticism.

PAUL T VAITKUS Cardiology Unit, 1-McClure, Medical Center Hospital of Vermont, University of Vermont, Burlington, VT 05401,

USA

1 O'Neill W, Timmis GC, Bourdillon PD, et al. A prospective randomized clinical trial of intracoronary streptokinase versus coronary angioplasty clinical trial of intracoronary streptokinase versus coronary anging

2 DeWood MA, Fisher MJ. Direct PTCA versus intravenous r-tPA in acute myocardial infarction: preliminary results from a prospective randomized trial. Circulation 1989;80:II-418.

3 Grines CL, Browne KF, Marco J, et al. A comparison of immediate angioplasty with thrombolytic therapy for acute myocardial infarction. $N$ Engl Med 1993;328:673-9.

4 Gibbons RJ, Holmes DR, Reeder GS, Bailey KR, Hopfenspirger MR, Gersh BJ. Immediate angioplasty compared with the administration of a thrombolytic agent followed by conservative treatment for myocardial infarction. $N$ Engl $₹$ Med 1993;328:685-91.

5 de Boer MJ, Hoorntje JCA, Ottervanger JP, Reiffers S, Suryapranata H, Zijlstra F. Immediate coronary angioplasty versus intravenous streptokinase in acute myocardial infarction: left ventricular ejection fraction, hospital mortality, and reinfarction. $\Im$ Am Coll Cardiol 1994;23:1004-8.

6 Ribeiro EE, Silva LA, Carneiro R, et al. Randomized trial of direct coronary angioplasty versus intravenous streptokinase in acute myocardial infarction. $\Im \mathrm{Am}$ Coll Cardiol 1993;22:376-80.

7 Elizaga J, Garcia EJ, Delcan JL, et al. Primary coronary angioplasty versus systemic thrombolysis in acute anterior myocardial infarction: in-hospital systemic thrombolysis in acute anterior myocardial infarction: in-hospital

8 Stone GW, Grines CL, Browne KF, et al. Primary angioplasty reduces inhospital mortality and morbidity in acute anterior myocardial infarction: hospits of the Primary Angioplasty in Myocardial Infarction (PAMI) trial results of the Primary Angioplasty in M

9 Vaitkus PT. Percutaneous transluminal coronary angioplasty versus thrombolysis in acute myocardial infarction: a meta-analysis. Clin Cardiol 1995;18:35-8.

10 McKendall GR, Drew TM, Kelsey SF, McDonald MJ, Sharaf BL, Thomas ES, Williams DO. What is the optimal treatment for thrombolytic ineligible AMI?: preliminary results of the Study of Medicine versus Angioplasty Reperfusion Trial (SMART) [abstr]. F Am Coll Cardiol 1994;23:225.

11 Berger PB, Bell MR, Holmes DR, Gersh BJ, Hopfenspirger M, Gibbons $\mathbf{R}$. Time to reperfusion with direct coronary angioplasty and thrombolytic therapy in acute myocardial infarction. Am $\$$ Cardiol 1994;73: 231-6.

12 Ryan TJ, Bauman WB, Kennedy JW, et al. Guidelines for percutaneous transluminal coronary angioplasty: a report of the American College of Cardiology/American Heart Association task force on assessment of diagnostic and therapeutic cardiovascular procedures (committee on percutaneous transi

13 Vaitkus PT. The continuing evolution of percutaneous transluminal coronary angioplasty in the treatment of coronary artery disease. Coronary Artery Disease (in press)

14 Goldberg RJ, Gore JM, Alpert JS, et al. Cardiogenic shock after acute myocardial infarction: incidence and mortality from a community-wide perspective, 1975 to 1988 . N Engl f Med 1991;325:1117-22.

15 Talley JD, Weiner BH, Etka W, et al. Clinical and angiographic profile of patients revascularized for cardiogenic shock: results from an international registry [abstr]. Clin Res 1994;42:292.

16 Lee L, Bates ER, Pitt B, Walton JA, Laufer N, O'Neill WW. Percutaneous transluminal coronary angioplasty improves survival in acute myocardia infarction complicated by cardiogenic shock. Circulation 1988;78: $1345-51$.

17 Hochman J, Boland J, Sleeper LA, et al. Current spectrum of cardiogenic shock and effect of early revascularization on mortality: results of an international registry. Circulation 1995;91:873-81.

18 O'Neill WW. Angioplasty therapy of cardiogenic shock: are randomized trials necessary? $f$ Am Coll Cardiol 1992;19:915-17. 